DOI:10.17951/h.2019.53.4.43-52

\begin{tabular}{lcc}
\hline \multicolumn{1}{c}{ A N N A L E S } \\
UNIVERSITATIS MARIAE CURIE-SKŁODOWSKA \\
LUBLIN - POLONIA \\
VOL. LIII, 4 & SECTIOH H \\
\hline
\end{tabular}

JOANNA ALICJA DYCZKOWSKA

jdyczkowska@wp.pl

Koszalin University of Technology. Faculty of Economic Sciences

6e Kwiatkowskiego St, 75-343 Koszalin, Poland

ORCID ID: http://orcid.org/0000-0001-9866-3897

\title{
The Active Customer in Logistics Services
}

Keywords: customer activity; logistics service; management of logistics services

JEL: D21; L89; O30

How to quote this paper: Dyczkowska, J.A. (2019). The Active Customer in Logistics Services. Annales Universitatis Mariae Curie-Skłodowska, sectio H-Oeconomia, Vol. 53, No. 4.

\begin{abstract}
This article describes the notion of "customer activity" in logistics services as an interaction with providers. We reviewed concepts of customer activity in services offered by logistics service providers (LSPs) in the food sector. We then analysed customer activity in transport, storage and management of services. We used a direct diagnostic survey for comparative analysis of groups of customers. The roles of LSPs in the supply chain and within the framework of cooperation in the business-to-business market are presented. Basic customer activities were examined by studying the supply chain, within which LSPs adapted their processes to the activities of their customers. The research results present the degree of customer activity in supply chains.

Theoretical background: Customer activity in logistics services is mainly understood as part of interaction with providers. This study goes beyond this view by focusing on the independent activity of the customer in solutions related to transport, storage and the management of logistics services.

Purpose of the article: The purpose of the article was to review concepts of customer activity in services offered by LSPs in food-sector supply chains; customer activity was characterised and applied in exploratory research.

Research methods: A literature review, comparison of groups of customers, and a direct diagnostic survey method were all used.
\end{abstract}


Main findings: The perspective of customer activity predominating among customers allows LSPs to pursue different activities on behalf of different groups of customers. This article contributes to research on logistics services while focusing on the concept of customer activity.

\section{Introduction}

The customer's activity in logistics services is mainly understood as part of interaction with providers. This article goes beyond this view, while focusing on the customer's independent activity, that is interaction in logistics services for solutions related to transport, storage and management of logistics services. The notion of "customer activity" remains undiscovered or unresolved to a large extent; hence, the purpose of this article is to develop the concept of customer activity in logistics services and to demonstrate the way in which the concept may be used in empirical research. The article reviews the concept of customer activity in logistics services within food-sector supply chains; then, customer activity is characterised and applied in exploratory research. The research juxtaposes customer activity, from the perspective of the operator's interaction, with the activities of providers, manufacturers and consumers from their perspective. This article includes a review of publications, a comparison of different customer groups, and research using a direct diagnostic survey method. The perspective on customer activity predominant among customers allows logistics service providers (LSPs) to pursue different activities on behalf of different groups of customers. This article contributes to research on logistics services while focusing on the concept of customer activity.

\section{Logistics service providers}

It is accepted that integration of supply chains has both strategic and operational significance (Christopher, 1997; Lambert, Cooper, \& Pagh, 1998; Frohlich \& Westbrook, 2001; Zailani \& Rajagopal, 2005). It is perceived as the basic activity of business logistics, operations, and management of supply chains, in which higher service productivity is ensured by specialised service providers (e.g. Rodrigues, Stank, \& Lynch, 2004; Cousins \& Menguc, 2006; Germain \& Iyer, 2006; Fabbe-Costes $\&$ Jahre, 2007). Another issue is the general trend for outsourcing logistics which has become widespread in Europe since the 1980s (van Laarhoven, Berglund, \& Peters, 2000). In Poland, this trend began between the late 1990s and the beginning of the 2000s, with increasing use of LSPs and changes in the relationship between forwarders and LSPs (Bask, 2001; Makukha \& Gray, 2004). Companies now outsource not only distribution, but also storage, management activities connected with the flow of goods, and complete handling of the distribution channel. At the same time, LSPs have developed their capacity to offer a wider range of services, and provide solutions adapted to specific customers or customer segments. In a growing 
number of companies, a significant part of the supply chain is outside their external borders. Some LSPs - known as fourth-party logistics (4PL) providers - may act as consultants, and even replace forwarders in the project and manage supply chains (Fulconis, Saglietto, \& Pache, 2006). 4PL providers are useful integrators in supply chains to improve competencies, and increase the operational potential of cooperation between companies.

The sets of abilities, processes and procedures used jointly to create synergy to overcome market challenges are considered in relation to logistics operators. Various logistics resources, such as physical, human, information, knowledge, and relational resources, can be analysed, and may be combined into a package to help achieve a permanent competitive advantage (Yew Wong \& Karia, 2010; Somsuk, Wonglimpiyarat, \& Laosirihongthong, 2012; Phusavat, Comepa, Sitko-Lutek, \& Ooi, 2013). However, these authors have argued that, owing to integration, it is possible to find empirical evidence for how pooling resources as part of cooperation enables companies to be competitive in the market. There is little research that examines how the process of integration within the distribution channel influences customer satisfaction, and to what extent the customer participates in the creation of the service. Furthermore, there are differences between LSPs in the services provided because integration does not take place at the same pace. Light needs to be shed, therefore, on how teams of company employees cooperate with 4PL providers within the framework of supply chains to increase potential and gain competitive advantage.

In this article, we propose a framework of cooperation for operational capacity based on a model of services offered to companies (B2B - business to business). We investigate and survey ten supply chains in the B2B market (i.e. food companies) in Middle Pomerania.

\section{Customer activity}

Every business organisation's success depends on customer satisfaction (Khadka $\&$ Maharjan, 2017). Interaction, one of the basic conceptions in service marketing (Grönroos, 2009), sums up the customer's role in that creation of value for the customer is the result of interactions between the customer and the company. Interactions are perceived as the building blocks for forming relationships that are at the core of logistics service marketing (Ballantyne \& Varey, 2006). While research has usually concentrated on interactions within the service or the company, some studies have approached customer relationship management from the viewpoint of the customer as the primary focus within a network of relationships (Law, Lau, \& Wong, 2003) or as the lone participant in impersonal service transactions exemplified by self-service (Fitzsimmons, 2003). In these approaches, customer activity is perceived as one that is managed by the service project or as a direct input of the customer in relation to the provider. 
Logistics operators hold the view that they offer an innovative conception of the customer's role as one of co-creation of a service. Co-creation enables the customer to collaborate with the provider to create a service, and thereby personalise it. This includes cooperation between the provider and customer to define the problem and find a solution, and emphasizes the active entry of the customer into the service process (Grönroos \& Voima, 2012). Although customer activity is at the centre of both interaction and integration of resources, the very notion of "activity" has not been defined nor explained in any way. Instead, the term is used in a general way to refer to any kind of behaviour. In addition, because interaction is such a dominant concept in the service model, independent customer activity, which remains outside of interaction, seldom appears in analyses. Solutions should be based on customer activities which signify the ways in which customers use different providers of logistics services to support their existing problems of supply and distribution. Customers purchase activities that are part of ongoing cycles, which include purchase, storage, packaging, and distribution. An approach focused on customer activity is generally accepted, yet without specifying what is understood by the notion of "customer activity".

The lack of any definition of "activity" is a fundamental problem when discussing customer activity in research on services or even on general marketing and logistics. Authors often use terms such as "activity", "action" and "behaviour" without defining their meaning. A review of the literature suggests that the reason may be that research on services has a strong tradition of focusing on interactions and relationships. The service is usually perceived through interactions between two or more parties, and not by how one party uses the results of an interaction. However, what is required is an approach emphasising the customer, in which the service is viewed from the customer's perspective (Heinonen, Strandvik, \& Voima, 2013). Understanding the service from the customer's perspective should not be limited to the interaction between the customer and the provider, but it should also consider other customer activities related to value for the customer. Logistics activities which are part of the process of creating value in the supply chain and within the customer's sphere, are fundamental, yet they are invisible to the provider. Although activities within the customer's domain are beyond the provider's awareness and direct influence, they are essential to the process of value creation by the customer. Such activities may include searching supplementary information on packaging, interactions with the company's competitors, interactions with providers of supplementary services, or interactions with other entities. Accurate predictions of a customer's activity status and future purchase propensities are crucial for managing customer relationships (Zhang, Bradlow, \& Small, 2015; Platzer \& Reutterer, 2016).

Connected activities may be other supplementary actions that customers become involved in before using a service, such as preparation of a schedule of supplies for production or for a network of customers. This view of customer activity may be described as a conceptual scenario in the handling of supplies to customers and as an 
experience in providing value in the chain, all of which concentrate on understanding the sequence of customer activities during provision of a service. These connected activities have an indirect impact on creation of value within the framework of basic (transport and movement of cargo) and related (storage, packing, and financial services) activities. For example, they may be unrelated events around which the core activity is realised. Although such activities are not directly involved in the process of value creation, they still exert an influence on its structure. Any analysis should account for the time when a logistics service is used, because timing of transport and storage, for example, during holidays, can have a significant impact on the value chain. In B2B research, the effects of customer activity are known, in part because logistics service providers must frequently adapt their processes to their customers' activity. However, it is necessary to clearly describe "activity" to identify and interconnect known levels of customer activity.

\section{Research methodology}

Seventy-five production companies were included in this research; of these, 10 companies had a food profile and were located in Middle Pomerania. The companies were surveyed to indicate their providers and customers to whom they were connected through a supply chain in the territory where they operated. This was accomplished using a method of interrelated companies (a variation of the snowball sampling method based on interpersonal relations inside a given organisation). Using this method, 10 responses were obtained from providers of food components and 10 - from market intermediaries, i.e. grocery shops or warehouses. The survey was carried out in 2015-2017. In this case, sample selection was not random; its aim was to distinguish 10 supply chains in the food sector.

The study addressed the following hypotheses:

H1: What recurring activities of customers of logistics services belong to the same system of value creation as those realised by the logistics operator?

$\mathrm{H} 2$ : Can any connections be found between activities identified for given groups of customers?

H3: What is the role of the LSP in the customer activity system?

\section{Results}

In this study, $80 \%$ of the providers of logistics services to production companies were small-sized companies, while $20 \%$ were medium-sized; $40 \%$ of the providers operated at a national scale and $60 \%$ - at an international scale. All the companies operated on the forwarder's side, but $30 \%$ also operated on the customer's side. Fifty percent of the providers dispatched parcels, $20 \%$ - single goods, and $30 \%$ dealt with 
part-cargos. In $70 \%$ of the cases, goods were sent every day, and in $30 \%$ of the cases once a week at a minimum.

Production companies operated both on the side of the consignor and of the customer. Thirty percent of these companies sent goods every day and $70 \%$ - once a week. In the case of manufacturers, $70 \%$ sent consignments, $20 \%$ - single goods, and $10 \%$ - part-loads. Half the producers sold only nationally, but the other half traded their products within Poland and abroad. In terms of size, $20 \%$ were smallsized companies, $40 \%$ were medium-sized companies, $30 \%$ were big production plants, and $10 \%$ were large companies.

Customers of the production companies were the third group, and included trading companies (warehouses and grocery shops). All of these were consignees, but $50 \%$ of them also sent back or sent goods on further. In the case of goods dispatched further, $60 \%$ were parcels and $40 \%$ were single goods; daily deliveries accounted for $30 \%$, minimum once-a-week deliveries for $60 \%$, and once a month deliveries for $10 \%$ of these transactions. In this group, $40 \%$ were small-sized, $50 \%$ were medium-sized, and $10 \%$ were large companies. All companies traded within Middle Pomerania only.

The companies studied carried out their operations in relation to those of the logistics operator by performing activities within the confines of the logistics service. Interactions were perceived as elements that built relationships, which were part of the logistics service provided by the logistics operator. Table 1 presents the active share of the customer of logistics services by function performed (by providers, producers and customers) in the supply chain related to transport.

Table 1. Customer activity related to transport in a logistics service process for 10 supply chains in the food sector in Middle Pomerania (Poland) in 2015-2017. The percentages represent the active participation of companies in a given logistics service

\begin{tabular}{|l|c|c|c|}
\hline \multicolumn{1}{|c|}{ Type of activity } & $\begin{array}{c}\text { Logistics } \\
\text { providers (\%) }\end{array}$ & $\begin{array}{c}\text { Manufacturers } \\
(\%)\end{array}$ & $\begin{array}{c}\text { Trading } \\
\text { companies }(\%)\end{array}$ \\
\hline Issuing an online bill of lading & 100 & 100 & 50 \\
\hline Identification of consignment (shipping tag) & 100 & 100 & 100 \\
\hline Preparation of products and consignment packaging & 100 & 100 & 100 \\
\hline Planning of deliveries & 100 & 100 & 50 \\
\hline Consignment tracking and notifying the customer & 70 & 100 & 20 \\
\hline
\end{tabular}

Source: Author's own study.

Food-sector production companies acted interactively in $100 \%$ of the cases to cooperate with the logistics service provider (Table 1). Logistics operators provided solutions related to transport in the following areas:

- issuing an online bill of lading, which contributed information on how many and what consignments were to be collected and on filling lines in given directions,

- consignment identification, printout of the codes for the customer's regions, including barcodes to enable fast recognition of the consignment and scanning, 
- preparation of products with packing, allowing a reduction in costs to the logistics operator (but frequently the operator provided pallets and stretch-type foil),

- planning of deliveries, with a good system for providing information for effective cooperation in scheduling vehicles and routes, which contributed to optimisation of transport for the logistics operator, and

- consignment tracking and notifying the customer, enabling interactions in the delivery of consignments.

Logistics providers in the supply chain fully participated in activities relating to transport except for consignment tracking (70\%; Table 1). All trading companies (customers), given their role in the supply chain, provided pack goods and shipping tags for consignments; in these cases, the logistics operator collected the consignment without fulfilling these activities. In sending goods on further, the trading companies issued online consignment notes and planned deliveries in 50\% of the cases. However, the trading companies' engagement in tracking consignments and providing information on delivery was minimal $(20 \%$; Table 1$)$.

Table 2. Customer activity related to storage in a logistics service process for 10 supply chains in the food sector in Middle Pomerania (Poland) in 2015-2017

\begin{tabular}{|l|c|c|c|}
\hline \multicolumn{1}{|c|}{ Type of activity } & Logistics providers (\%) & Manufacturers (\%) & Trading companies (\%) \\
\hline Consolidation of cargo & 100 & 100 & 20 \\
\hline Handling of returns & 20 & 60 & 70 \\
\hline Storage of products & 10 & 30 & 100 \\
\hline Selection of location & 100 & 100 & 50 \\
\hline
\end{tabular}

Source: Author's own study.

The extent of customer activity in relation to storage solutions used by LSPs is presented in Table 2. All logistics providers and manufacturers were involved in consolidation of cargo and selection of the location. Providers of materials in logistics chains did not handle returns and did not store products. All trading companies interacted in the case of storage and most companies in handling returns $(70 \%)$. However, their interaction was minimal in consolidation of cargo, and only half were involved in location selection.

Table 3. Customer activity related to management of a logistics service process for 10 supply chains in the food sector in Middle Pomerania (Poland) in 2015-2017

\begin{tabular}{|l|c|c|c|}
\hline \multicolumn{1}{|c|}{ Type of activity } & $\begin{array}{c}\text { Logistics } \\
\text { providers (\%) }\end{array}$ & $\begin{array}{c}\text { Manufacturers } \\
(\%)\end{array}$ & $\begin{array}{c}\text { Trading } \\
\text { companies (\%) }\end{array}$ \\
\hline Analysis of cargo streams & 20 & 60 & 0 \\
\hline Verification of the supply chain status and benchmarking & 20 & 80 & 0 \\
\hline Global development of procurement strategies & 0 & 50 & 0 \\
\hline Expertise in categories and acquisition of providers & 0 & 60 & 20 \\
\hline Planning and coordination of supply chain & 20 & 90 & 10 \\
\hline
\end{tabular}

Source: Author's own study. 
Customer activities in management of logistics services are shown in Table 3. Logistics providers and trading companies in the supply chain did not participate in active management of the logistics service process. Production companies in the food sector, as the most important link in the supply chain, engaged significantly in managing logistics services, especially in the planning and coordination of activities in the supply chain $(90 \%)$ and verification of the status of the supply chain and benchmarking (80\%). They were involved in analysis of cargo streams to a lesser extent. Companies that operated at an international level demonstrated expertise in categories and acquisition of providers, and were active in global development of procurement strategies.

\section{Discussion}

Customers of logistics services actively participate in the creation of added value in the supply chain, and active participation can be differentiated by service type and customer group. Interactions are perceived as those elements that build relations with LSPs within the scope of transport, storage, and management of logistics services. The logistics operator is an integrator in the supply chain by enabling active participation of the customer in the logistics service. This article is the first to show how customers combine different activities (where interaction with services is only one type of activity) in the systems that they maintain to create value for themselves. By profiling customers according to the position they occupy in the supply chain, their roles can be understood in the network of activities that create added value.

\section{Conclusions}

Food-sector manufacturers take a leading role in the management of logistics service processes, and actively participate in all logistics activities. Suppliers to manufacturers act in the area of transport and, to a lesser extent, in storage, but they do not actively manage service processes. The role of trading companies in logistics services is smaller compared to the roles of manufacturers and their logistics providers. Activity in logistics services depends on the position occupied in the supply chain and on cooperation with the logistics operator. Manufacturers assessed cooperation with LSPs on very high and high levels $(80 \%)$ and on an average level $(20 \%)$. Suppliers of raw materials assess cooperation with the provider of services on very high and high levels (70\%) and on an average level (30\%), and trading companies rate it high and average (50\% each). This study demonstrates that customers are actively involved in logistics services provided by LSPs, empowered by the modern IT systems offered by the latter. 


\section{References}

Ballantyne, D., \& Varey, R.J. (2006). Creating value-in-use through marketing interaction: The exchange logic of relating, communicating and knowing. Marketing Theory, 6(3). doi:10.1177/1470593106066795

Bask, A. (2001). Relationships among TPL providers and members of supply chains - a strategic perspective. Journal of Business \& Industrial Marketing, 16(6). doi:10.1108/EUM0000000006021

Christopher, M. (1997). Marketing Logistics. Oxford: Butterworth-Heinemann.

Cousins, P.D., \& Menguc, B. (2006). The implications of socialization and integration in supply chain management. Journal of Operations Management, 24(5). doi:10.1016/j.jom.2005.09.001.

Fabbe-Costes, N., \& Jahre, M. (2007). Supply chain integration gives better performance: The Emperor's new suit? International Journal of Physical Distribution \& Logistics Management, 37(10). doi:10.1108/09600030710848941

Fitzsimmons, J.A. (2003). Is self-service the future of services? Managing Service Quality, 13(6). doi:10.1108/09604520310506496

Frohlich, M.T., \& Westbrook, R. (2001). Arcs of integration: an international study of supply chain strategies. Journal of Operations Management, 19(2). doi:10.1016/S0272-6963(00)00055-3

Fulconis, F., Saglietto, L., \& Pache, G. (2006). Exploring new competences in the logistics industry: The intermediation role of 4PL. Supply Chain Forum: An International Journal, 7(2). doi:10.1080/16258312.2006.11517170

Germain, R., \& Iyer, K.N.S. (2006). The interaction of internal and downstream integration and its association with performance. Journal of Business Logistics, 27(2). doi:10.1002/j.2158-1592.2006.tb00216.x

Grönroos, C. (2009). Relationship marketing as promise management. In: P. Maclaran, M. Saren, B. Stern, M. Tadajewski (Eds.), The SAGE Handbook of Marketing Theory. London: SAGE.

Grönroos, C., \& Voima, P. (2012). Critical service logic: making sense of value creation and co-creation. Journal of the Academy of Marketing Science, 41(2). doi:10.1007/s11747-012-0308-3

Heinonen, K., Strandvik, T., \& Voima, P. (2013). Customer-dominant value formation in service. European Business Review, 25(2). doi:10.1108/09555341311302639

Khadka, K., \& Maharjan, S. (2017, November). Customer satisfaction and customer loyalty. Centria University of Applied Sciences, Business Management.

Laarhoven, P. van, Berglund, M., \& Peters, M. (2000). Third-party logistics in Europe - five years later. International Journal of Physical Distribution \& Logistics Management, 30(5). doi:10.1108/09600030010336216

Lambert, D.M., Cooper, M.C., \& Pagh, J.D. (1998). Supply chain management: implementation issues and research opportunities. International Journal of Logistics Management, 9(2). doi:10.1108/09574099810805807

Law, M., Lau, T., \& Wong, Y.H. (2003). From customer relationship management to customer-managed relationship: Unraveling the paradox with a co-creative perspective. Marketing Intelligence \& Planning, 2l(1). doi:10.1108/02634500310458153

Makukha, K., \& Gray, R. (2004). Logistics partnerships between shippers and logistics service providers: The relevance of strategy. International Journal of Logistics Research and Applications, 7(4). doi: $10.1080 / 13675560412331322952$

Phusavat, K., Comepa, N., Sitko-Lutek, A., \& Ooi, K.-B. (2013). Productivity management: Integrating the intellectual capital. Industrial Management \& Data Systems, 113(6). doi:10.1108/IMDS-09-2012-0330

Platzer, M., \& Reutterer, T. (2016). Ticking away the moments: Timing regularity helps to better predict customer activity. Marketing Science, 35(5). doi:10.1287/mksc.2015.0963

Rodrigues, A.M., Stank, T.P., \& Lynch, D.F. (2004). Linking strategy, structure, process, and performance in integrated logistics. Journal of Business Logistics, 25(2). doi:10.1002/j.2158-1592.2004.tb00182.x 
Pobrane z czasopisma Annales $\mathrm{H}$ - Oeconomia http://oeconomia.annales.umcs.pl Data: 26/04/2023 07:42:13

Somsuk, N., Wonglimpiyarat, J., \& Laosirihongthong, T. (2012). Technology business incubators and industrial development: Resource-based view. Industrial Management \& Data Systems, 112(2). doi:10.1108/02635571211204281

Yew Wong, C., \& Karia, N. (2010). Explaining the competitive advantage of logistics service providers: A resource-based view approach. International Journal of Production Economics, 128(1). doi:10.1016/j.ijpe.2009.08.026

Zailani, S., \& Rajagopal, P. (2005). Supply chain integration and performance: US versus East Asian companies. Supply Chain Management: An International Journal, 10(5). doi:10.1108/13598540510624205

Zhang, Y., Bradlow, E.T., \& Small, D.S. (2015). Predicting customer value using clumpiness: From RFM to RFMC. Marketing Science, 34(2). doi:10.1287/mksc.2014.0873 